\title{
On the Inclusion of Blind People in UML e-Learning Activi- ties
}

\author{
Sobre a Inclusão de Pessoas Cegas em Atividades de Ensino Eletrônico de UML
}

Leandro Luque

Escola Politécnica

University of Sao Paulo (USP)

Sao Paulo State Technological College

Fatec Mogi das Cruzes (Fatec-MC)

leandro.luque@usp.br

Romero Tori

Escola Politécnica

University of Sao Paulo (USP)

tori@usp.br

\author{
Leônidas de Oliveira Brandão \\ Institute of Mathematics and Statistics \\ University of Sao Paulo (USP) \\ leo@ime.usp.br
}

\author{
Anarosa Alves Franco Brandão \\ Escola Politécnica \\ University of Sao Paulo (USP) \\ anarosa.brandao@usp.br
}

\begin{abstract}
The UML - Unified Modeling Language is a standard notation for software development, which has been widely adopted in academy and industry worldwide. However, the inclusion of blind people in UML-related activities is still a challenge, mostly due to the extensive use of its graphical notation. There are several actions that can promote the inclusion of blind people when considering the application of face-to-face UML classes, such as the use of physical devices to represent diagram elements( e.g. illustrative objects and pens for tactile drawings). Needless to say, these actions are not effective in e-learning activities because participants do not share the same physical space. In this context, this paper addresses the problem of including blind people in e-learning activities of UML. First, it establishes the requirements needed for such inclusion by combining the information gathered from a literature review (conducted to identify studies related to the accessibility of UML diagrams by blind people) with the experience from one of the authors in teaching UML for blind learners. Secondly, it analyzes tools that support the accessible representations of UML diagrams and evaluates them regarding the fulfillment of the proposed requirements. The results indicate a lack of solutions that enable the inclusion of blind people in such activities without being affected by the transactional distance, i.e. the learner perceptions concerning distance. Finally, the paper presents the strategies, design patterns and frameworks, considered to develop a web-based prototype of a learning tool that fulfills the established requirements. Directions for future research are presented at the end of the paper.
\end{abstract}

Keywords: UML - Unified Modeling Language, e-Learning, Accessibility, Blind, Requirements

\footnotetext{
Resumo A UML - Linguagem de Modelagem Unificada é uma notação padrão para o desenvolvimento de software, amplamente adotada na academia e na indústria em todo o mundo. Devido ao uso quase exclusivo da sua notação gráfica, a inclusão de pessoas cegas em atividades baseadas em UML ainda é um desafio. No que diz respeito à educação presencial de UML, existem várias medidas que podem contribuir para superar este desafio, tal como o uso de objetos fisicos para representar elementos de diagramas - exemplos incluem objetos ilustrativos e canetas para desenho em alto relevo. Estas soluções permitem a condução de atividades colaborativas entre participantes cegos e de visão normal. No entanto, estas medidas não são efetivas em atividades de ensino eletrônico dada a distância física entre os participantes. Neste contexto, este artigo
} 
aborda o problema da inclusão de pessoas cegas em atividades de ensino eletrônico de UML. Inicialmente, o artigo estabelece os requisitos necessários para tornar essa inclusão possivel por meio de uma revisão da literatura conduzida para identificar estudos relacionados à acessibilidade de diagramas UML para pessoas cegas combinado à experiência de um dos autores em lecionar UML para aprendizes cegos. Ademais, o artigo analisa ferramentas que permitem a representação de diagramas UML em formato acessível a pessoas cegas, bem como avalia estas ferramentas quanto ao cumprimento dos requisitos estabelecidos. Os resultados indicam a carência de soluções que permitem a inclusão de pessoas cegas nestas atividades sem afetar a distância transacional, ou seja, a percepção de distanciamento sentida pelo aluno em atividades de aprendizagem. Por fim, o artigo apresenta as estratégias, padrões de projeto e frameworks considerados na implementação de um protótipo de ferramenta web que atende aos requisitos estabelecidos. Na parte final do artigo, direções para trabalhos futuros são apresentadas.

Palavras-Chave: UML - Linguagem de Modelagem Unificada, Ensino Eletrônico, Educação a Distância, Acessibilidade, Cego, Requisitos 


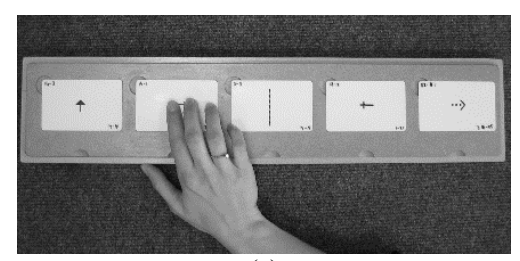

(a)

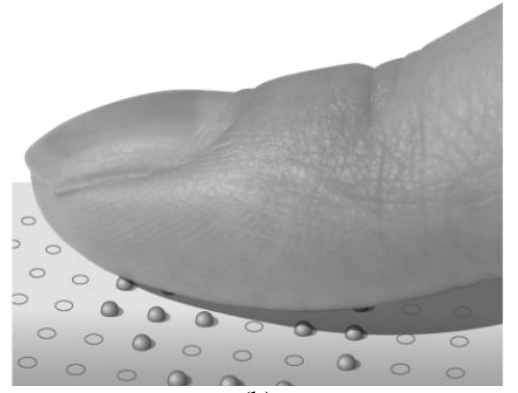

(b)

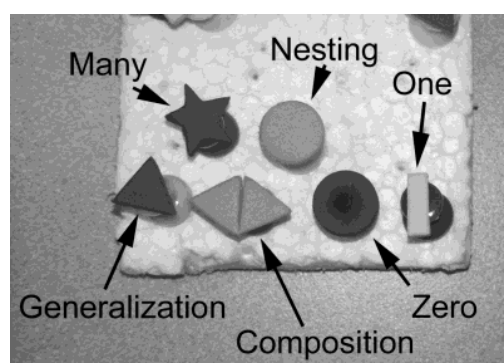

(c)

Figure 1: (a) Symbols created with PVC cards [28] (b) Tactile display illustration (c) Physical objects used to represent UML elements [9].

\section{Introduction}

According to the World Health Organization [1], the number of visually impaired people worldwide is estimated to be 285 million, of which 39 million are blind. In Brazil, these numbers are estimated at 35 million and 730.000 respectively [2]. Information and Communication Technologies (ICT) play an important role in the social inclusion of blind people, mainly due to its potential to provide means for accessing information, products and digital services. It can be very important to circumvent the physical environments lack of accessibility in many cities (e.g. public transportation, sidewalks, and traffic lights). However, many tools used in Computer Science (CS) and Computing Engineering (CE) fields are still inaccessible $[3,4]$.

When considering the inclusion of blind people in computer education programs and in the software development industry, the frequent required use of graphs and diagrams creates accessibility barriers. Examples of these graphs and diagrams include Entity Relationship Diagrams (ERD) [5], Data Flow Diagrams (DFD) [6], and Unified Modeling Language (UML) diagrams [7].

UML is one of the most used notations to understand, specify and document, object oriented software systems $[8,9]$. It is widely adopted by the industry and it usually appears in reference curriculums of the field $[10,11,12,13,14,15]$. Its current version, UML 2.4.1, presents 14 different types of diagrams that can be applied along different software development phases and disciplines, such as business modeling, requirements, design, and so on. The UML specification is maintained by the Object Management Group (OMG) [16].

In computer education programs, many instructors use UML diagrams to teach object oriented concepts [9], and blind learners are usually not allowed to express their knowledge through alternative tasks [17]. Therefore, in order to convey the graphical information in classroom activities, instructors have to use tools such as pens, papers or printers for tactile drawings [18] (Figure 1a), tactile displays [19] (Figure 1b), physical objects with specific semantics $[9,20,21]$ (Figure 1c), among others.

Some of these tools, such as pens for tactile drawings and physical objects, allow instructors to conduct collaborative activities including blind and sighted learners (e.g. the creation of a diagram or the identification of errors in a previously created diagram). Despite the utility of these tools in traditional classrooms (face-to-face), their e-learning application is difficult. E-learning activities are those executed with a spatial and possibly temporal distances either between participants or content and participants [22]. These activities are essential in blended and distance learning programs, which have been growing worldwide $[23,24]$. Nonetheless, e-learning activities have also been used in traditional face-to-face education programs. Currently, there are more than 30 Brazilian institutions offering accredited blended and distance higher education courses in the computing fields [25].

The difficulty concerning the use of tools to support UML activities in e-learning arises mainly from the lack of physical interaction between participants, considering their spatial distance, as well as the limited availability of haptic devices, which have high cost input/output hardware for stimulating touch sensations, such as temperature, vibration, motion, and force [26].

One possible approach to reduce this difficulty is to define and prepare, in advance, accessible materials for the activities which content is diagram-related, allowing the instructors to deliver materials (e.g. tactile diagrams) to the learners before starting the activity. This, however, prevents the modification of the accessible materials during the activity, resulting in a static course. This inflexibility prevents free interactions between learners and the instructor, negatively influencing the educational processes. In addition, some authors [22, 27] advocate that the lower the flexibility of the course, the less opportunities for dialogue and interference during its develop- 
ment. Considering transactional distance, this inflexibility may increase the sense of distance between participants [27].

For the purposes of this work, transactional distance can be understood as the psychological and communication space to be crossed during interactions between instructors and learners [27], and it is increased by the occurrence of spatial or temporal distance. Hence, restricting diagram-related content may reduce the autonomy of blind learners resulting in discouragement. For instance, diagrams based on situations raised during class, which could increase the motivation of the learner, can no longer be applied in an inclusive scenario.

In this context, this paper addresses the problem of including blind people in e-learning activities involving UML as subject, aiming at reducing the impact of transactional distance. After discussing the main challenges of the inclusion of blind people in such activities, it establishes the requirements needed to apply this inclusion by combining the information gathered from literature review (conducted to identify studies related to the accessibility of UML diagrams for blind people) with the experience in teaching UML to blind learners from one of the authors. Additionally, it analyzes tools that support accessible representations of UML diagrams and evaluates them regarding the fulfillment of the proposed requirements. The results indicate the lack of solutions that enable the inclusion of blind people in such activities without being affected by transactional distance. Besides that, the paper presents some strategies, design patterns and frameworks considered to develop a web-based prototype for a tool that fulfills the established requirements.

The remainder of the paper is organized as follows: Section 2 provides a background on e-learning and accessibility. Section 3 describes the methodology followed. Section 4 presents the results of the literature review along with the tools that support accessible representations of UML diagrams. Section 5 establishes and discusses the requirements to include blind learners in elearning activities of UML. In section 6 , the tools and solutions proposed in the literature are analyzed considering the fulfillment of the requirements. Section 7 presents the strategies, design patterns and frameworks considered to develop a prototype that fulfills the proposed requirements. Finally, the conclusions are presented in Section 8.

\section{Background}

Blind people receive information mainly by hearing and touching. When interacting with computers, the information is generally transmitted by using sounds [29], haptic devices [30], Braille printers [31] and displays [19]. Data input is usually accomplished by using key- boards - menus and shortcuts - and voice commands [32]. Although touch is the most commonly used sense for accessing graphical information in classrooms, hearing is the sense used when interacting with computers since they already have sound interfaces established [29]. A common solution for this type of interface are screen readers. Such tools extract the textual information present in the screen and synthesize into sound in order to present it to the users. Unfortunately, screen readers cannot read pixels, which means that graphical interfaces impose several challenges to blind users.

Usually e-Learning Environments (e-LE) are applied in distance and blended learning to support interactions among instructors, learners and content [33]. They offer a variety of features, including: access control, course management, content management, virtual drive, instant messaging, whiteboard, among others [22]. Examples of e-LE include Moodle [34], Blackboard [35], Tidia-AE [36], and Teleduc [37]. An important aspect of e-LE is the degree of accessibility offered to users. Accessibility can be defined as the ease with which one accesses and uses products and services. When considering computing products, it is known as digital accessibility [38].

The accessibility of e-LE involves both technological and methodological aspects [24]. If one of these aspects is neglected, accessibility may be unsatisfactory. In addition, an environment developed in compliance with accessibility standards will not be accessible to blind users if the content delivered has been designed for sighted users, e. g. with graphs and charts lacking textual descriptions or support of haptic devices. Although many e-LE are technologically accessible [39], these environments still present a major concern with content accessibility. According to a survey conducted by Tabs et al. [40], 33\% of the institutions in the USA, offering online courses between the years of 2000 and 2001, reported not knowing if their systems were in compliance with the accessibility standards, 3\% did not follow standards and $18 \%$ followed only some aspects. No similar data from Brazilian institutions were available.

Considering the context where even e-LEs complying with accessibility standards could present accessibility issues regarding the content being delivered. This work analyzes which requirements are needed for integrating blind learners in e-LE activities, aiming at reducing the transactional distance. To limit the scope, this search focus only on activities involving UML diagrams.

\section{Method}

A review of the literature, for identifying studies related to the accessibility of UML diagrams, was performed in order to establish the requirements that enable the inclusion of the blind people in UML e-learning ac- 
tivities, aiming at reducing the impact of transactional distance .

The literature review was broad and involved the identification of references and citations related to the main studies published on the subject, assimilated in previous research [41]. The availability of proposed tools was also verified. The coverage of our literature review is broad and confirmed by a subsequent systematic literature review conducted by the authors, which results will be published elsewhere. The relevant studies of the literature review are listed in Section 4. Some of them present accessible tools that allow textual specifications of UML diagrams.

In order to verify if the identified tools were the only ones available to the end users, a new search was performed on 29/03/2015 considering the string ("UML from text" OR "textual UML" OR "UML textual" OR "UML em texto"). This search string is generally enough to raise any reference for tools that allow the specification of UML diagrams textually. All websites listed as relevant by the search engine (top 100 websites) were visited and those related to the tools were recorded. Thus, their official websites were visited in order to collect more information related to the availability of the tool (web or desktop) and the UML diagrams they support (see Table 1).

To establish the proposed requirements, the information gathered from both reviews (literature and tools) was combined with the information from the teaching experience of an Object Oriented Analysis course for blind learners. Finally, each solution and tool found were analyzed according to the fulfillment of the requirements established. It was concluded that none of the solutions raised covered all of the requirements.

Therefore, a web-based tool prototype is specified in this study attempting to cover all requirements. The following technological resources were adopted in order to develop the web-based prototype: Java Enterprise Edition platform with HTML 5, CSS 3 and JavaScript. The adoption of Java and web-based technologies was driven by portability, a desired non-functional requirement for this tool. Additionally, the popularity of these technologies facilitates its adaptation by other researchers.

\section{Literature Review}

Despite the large number of published studies investigating the accessibility of different types of graphs, there are not many studies on the accessibility of UML diagrams by blind people. Here, the relevant literature is briefly described regarding the issue discussed in Section 3.

King et al. [67] proposed a software system intended for enabling blind users to extract relevant technical content from diagram images. Although this specific project failed, it generated a sub product known as "Accessible UML", which reads XMI (XML Metadata Interchange) files of UML use case and class diagrams that commonly exported by Computer-Aided Software Engineering CASE tools. It presents the information in a graph which can be navigated by keyboard or joystick and accessed graphically or via audio. A graph node represents the item under inspection, for example class in a class diagram or Use Case in a use case diagram. However, it does not allow diagram editing. The software is available at www.alasdairking.me.uk/tedub/index.htm. Pansanato et al. [68] and Santos et al. [69] propose a tool that enables the accessing and editing of UML diagrams by blind people using different types of keyboard interaction.

Brookshire [20] reported his experience with the use of tactile cards for teaching diagrams to blind learners. His experience indicates that they can be used in interactive activities without spatial distance between participants. Müller [17] discussed her experience in teaching UML to two blind learners using tactile diagrams (Emprint-ViewPlus), combined with textual description, through a table structure (class, object, and state machine diagrams) and a message list (sequence diagram). No experiment was conducted to compare her approach with other existing ones.

Owen et al. [9] presented two strategies used to convey UML diagrams into information for blind people. The first involved the design of a tactile system for elements of class and state diagrams using rubber bands and push-pins. The second strategy was related to the development of a software called "Audible Browser", which reads XMI 2.1 files - as produced by Visual Paradigm and presents the nodes of class and state diagrams in an interactive tab group. The authors end the paper discussing some of the general aspects that must be present in UML translators and the future directions for their work. The tool was not available for download.

Silva et al. [70] proposed the use of worksheets to represent the content of the UML diagrams in a tabular form. According to them, it is a style of interaction familiar to blind people. They suggest possible representations of three UML diagrams: use cases, class and sequence diagram. Silva and colleagues reported that the strategy received a positive feedback from all participants involved in its use during an undergraduate course (teacher, blind and sighted learners).

Grillo et al. [71] proposed a technique for collaborative work between blind and sighted people, in which a textual and a graphical view for the same model are generated. When the model is updated using any of the 
views, both views are synchronized to reflect the update. A tool that implements this technique is available for download at http://garapa.intermidia.icmc.usp.br:3000/ awmo/textual.jsf.

\begin{tabular}{|c|c|c|c|c|c|c|c|c|c|c|c|c|c|c|c|}
\hline \multirow[t]{2}{*}{ Tool } & \multirow[t]{2}{*}{ Availability } & \multicolumn{14}{|c|}{ Supported Diagrams } \\
\hline & & 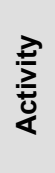 & $\begin{array}{l}0 \\
\mathscr{D} \\
\frac{\mathbb{O}}{U}\end{array}$ & 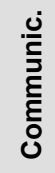 & $\begin{array}{l}\text { 등 } \\
\text { 등 } \\
\text { ํㅡㄹ } \\
\text { ㅇ }\end{array}$ & $\begin{array}{l}\text { ம் } \\
\dot{0} \\
\text { 을 } \\
\text { हे }\end{array}$ & $\begin{array}{l}\text { 등 } \\
\stackrel{0}{E} \\
\frac{0}{\alpha} \\
\frac{0}{0}\end{array}$ & 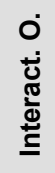 & $\begin{array}{l}\text { ঠே } \\
\stackrel{\oplus}{0} \\
0\end{array}$ & 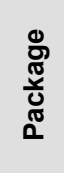 & $\frac{0}{\frac{0}{2}}$ & 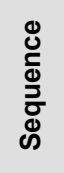 & $\stackrel{ \pm}{\stackrel{ \pm}{ \pm}}$ & 올 & 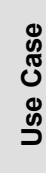 \\
\hline AWMo [42] & Web & & $\checkmark$ & & & & & & & & & & & & \\
\hline blockdiag [43] & Web and Desktop & $\checkmark$ & & & & & & & & & & $\checkmark$ & & & \\
\hline CodeUML [44] & Web & & & & & & & & & & & $\checkmark$ & & & \\
\hline Cwknc [45] & Web & & & & & & & & & & & $\checkmark$ & & & \\
\hline Diagrammr [46] & Web & & & $\checkmark$ & & & & & & & & $\checkmark$ & & & \\
\hline $\begin{array}{l}\text { Finite State M. D. } \\
\text { Gen. [47] }\end{array}$ & Web & & & & & & & & & & & & $\checkmark$ & & \\
\hline $\begin{array}{l}\text { js-sequence- } \\
\text { diagrams [48] }\end{array}$ & Web & & & & & & & & & & & $\checkmark$ & & & \\
\hline MetaUML [49] & Web & $\checkmark$ & $\checkmark$ & & & & & & & $\checkmark$ & & & $\checkmark$ & & $\checkmark$ \\
\hline Nomnoml [50] & Web & & $\checkmark$ & & & & & & & & & & & & \\
\hline $\begin{array}{l}\text { PlantTextUML Editor } \\
\text { [51] }\end{array}$ & Web & $\checkmark$ & $\checkmark$ & & $\checkmark$ & & & & $\checkmark$ & & & $\checkmark$ & $\checkmark$ & & $\checkmark$ \\
\hline PlantUML [52] & Web & $\checkmark$ & $\checkmark$ & & $\checkmark$ & & & & $\checkmark$ & & & $\checkmark$ & $\checkmark$ & & $\checkmark$ \\
\hline SeedUML [53] & Web & & & & & & & & & & & $\checkmark$ & & & \\
\hline Sequence flow [54] & Web & & & & & & & & & & & $\checkmark$ & & & \\
\hline UMLetino [55] & Web & $\checkmark$ & $\checkmark$ & & & $\checkmark$ & $\checkmark$ & & & $\checkmark$ & & $\checkmark$ & $\checkmark$ & & $\checkmark$ \\
\hline Umple [56] & Web & & $\checkmark$ & & & & & & & & & & $\checkmark$ & & \\
\hline $\begin{array}{l}\text { WebSequenceDia- } \\
\text { grams [57] }\end{array}$ & Web & & & & & & & & & & & $\checkmark$ & & & \\
\hline yUML [58] & Web & $\checkmark$ & $\checkmark$ & & & & & & & & & & & & $\checkmark$ \\
\hline EventStudio [59] & Desktop & & & & & & & & & & & $\checkmark$ & & & \\
\hline LightUML [60] & Desktop & & $\checkmark$ & & & & & & & & & & & & \\
\hline Modsl [61] & Desktop & & $\checkmark$ & $\checkmark$ & & & & & & & & & & & \\
\hline $\begin{array}{l}\text { Quick Sequence } \\
\text { Diagram Editor [62] }\end{array}$ & Desktop & & & & & & & & & & & $\checkmark$ & & & \\
\hline TextUML Toolkit [63] & Desktop & & $\checkmark$ & & & & & & & & & & & & \\
\hline UML Graph [64] & Desktop & & $\checkmark$ & & & & & & & & & $\checkmark$ & & & \\
\hline UMLet [65] & Desktop & $\checkmark$ & $\checkmark$ & & & $\checkmark$ & $\checkmark$ & & & $\checkmark$ & & $\checkmark$ & $\checkmark$ & & $\checkmark$ \\
\hline USE [66] & Desktop & & $\checkmark$ & & & & & & & & & & & & \\
\hline EasyUML Editor & Discontinued & & & & & & & & & & & & & & \\
\hline metaDepth & Not Found & & & & & & & & & & & & & & \\
\hline
\end{tabular}

Table 1: Tools, their availability and supported diagrams. 
Metatla et al. [72] also focus on collaborative work by presenting a strategy that supports multimodal interfaces (i.e. interfaces that combine two or more modalities of input and/or presentation). The tool set, known as $\mathrm{CCml}$, is available for download at: http://ccmi.eecs.qmul.ac.uk.

Loitsch and Weber [73] proposed an haptic and audio-based explorer, called "HyperReader", which allows blind people to access the information present in UML sequence diagrams. It can be integrated with Visio to enable the collaboration of sighted people.

In addition to studies on the accessibility of UML diagrams, some general approaches seek to make any type of diagram available [41]. Unfortunately, with only three exceptions [67, 71, 72], tools were not available for download and use.

Table 2 summarizes the studies described in this section and the representation strategies they support. Hierarchical strategy means presenting the information of a graph by navigating through a keyboard or a joystick, and accessed via audio, haptic devices or graphically. Graphical strategy means presenting a diagram in the default notation of UML. Tabular strategy means presenting the information using worksheets. In this table, the letter 'P' used in the row related to the work of Brookshire stands for 'Partially', meaning that the solution does not use the default notation of UML - it uses objects to represent the diagram elements.

\begin{tabular}{|c|c|c|c|c|c|}
\hline Study & 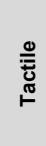 & 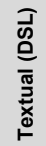 & $\frac{\frac{\hbar}{5}}{\frac{0}{5}}$ & 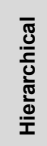 & $\begin{array}{l}\frac{0}{\pi} \\
\frac{0}{\frac{0}{0}} \\
\frac{\pi}{0}\end{array}$ \\
\hline $\begin{array}{l}\text { Owen et al. [9] - Audible } \\
\text { Browser }\end{array}$ & & & & $\checkmark$ & \\
\hline Müller [17] & $\checkmark$ & & $\checkmark$ & & $\checkmark$ \\
\hline Brookshire [20] & $\checkmark$ & & & & $\mathrm{P}$ \\
\hline $\begin{array}{l}\text { King et al. [67] - Accessible } \\
\text { UML }\end{array}$ & & & & $\checkmark$ & $\checkmark$ \\
\hline $\begin{array}{l}\text { Pansanato et al. [68] } \\
\text { And } \\
\text { Santos et al. [69] - D4ALL }\end{array}$ & & & $\checkmark$ & $\checkmark$ & $\checkmark$ \\
\hline Silva et al. [70] & & & $\checkmark$ & & \\
\hline Grillo et al. [71] - AWMo & & $\checkmark$ & & & $\checkmark$ \\
\hline Metatla et al. [72] - CCml & $\checkmark$ & & & & $\checkmark$ \\
\hline $\begin{array}{l}\text { Loitsch \& Weber [73] - Hy- } \\
\text { perReader }\end{array}$ & $\checkmark$ & $\checkmark$ & & & $\checkmark$ \\
\hline
\end{tabular}

Table 2: Studies and related representation strategies.

Regarding the tools searched and not cited in the reviewed studies, 100 sites considered relevant were visited, out of which 26 had references to tools (Table 1), conveying a total of 27 different web-base and desktop tools.

Each tool specifies a DSL (Domain Specific Language) that can be applied for specifying diagrams. DSL is a computer language focused on a particular domain. All of the tools allow the user to create visual representations of diagrams from textual specifications. For instance, Figure 2 presents a class diagram specified by DSL used in yUML, one of the most popular textual UML tools, which supports activities, use cases and class diagrams. Figure 3 shows the created diagram.

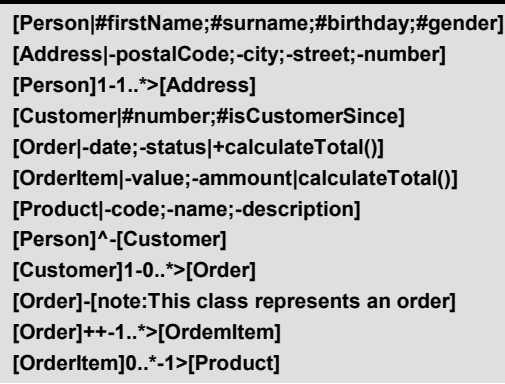

Figure 2: Class diagram specified with the yUML DSL.

\section{The Proposed Requirements}

In the conducted literature review it was observed that technological issues involved in the accessibility of UML diagrams are commonly addressed, but none of them addressed the UML learning activities with spatial distance or real-time interactivity, which are important components when considering transactional distance. Therefore, to define the requirements for including blind people in this type of activity, it is necessary to analyze the forms of interaction that can be established between instructors, learners and content during the learning/teaching process.

This analysis was based on the experience in teaching object-oriented analysis with UML, which led to consider five activities as common during the process: (i) presentation of diagrams and explanation of its structure/content; (ii) construction of diagrams step-by-step, individually or with collaboration; (iii) presentation of diagrams and questioning its structure/content problems; (iv) evaluation of diagrams created by third parties; and (v) peer reviews.

In order to consider the blind people integrated in the five activities quoted they should be able to: open an existing diagram, create and edit diagrams in accessible formats; make diagrams available to other participants; highlight and access in real-time any information on the elements of a diagram that other participants are highlighting or changing during presentations. 


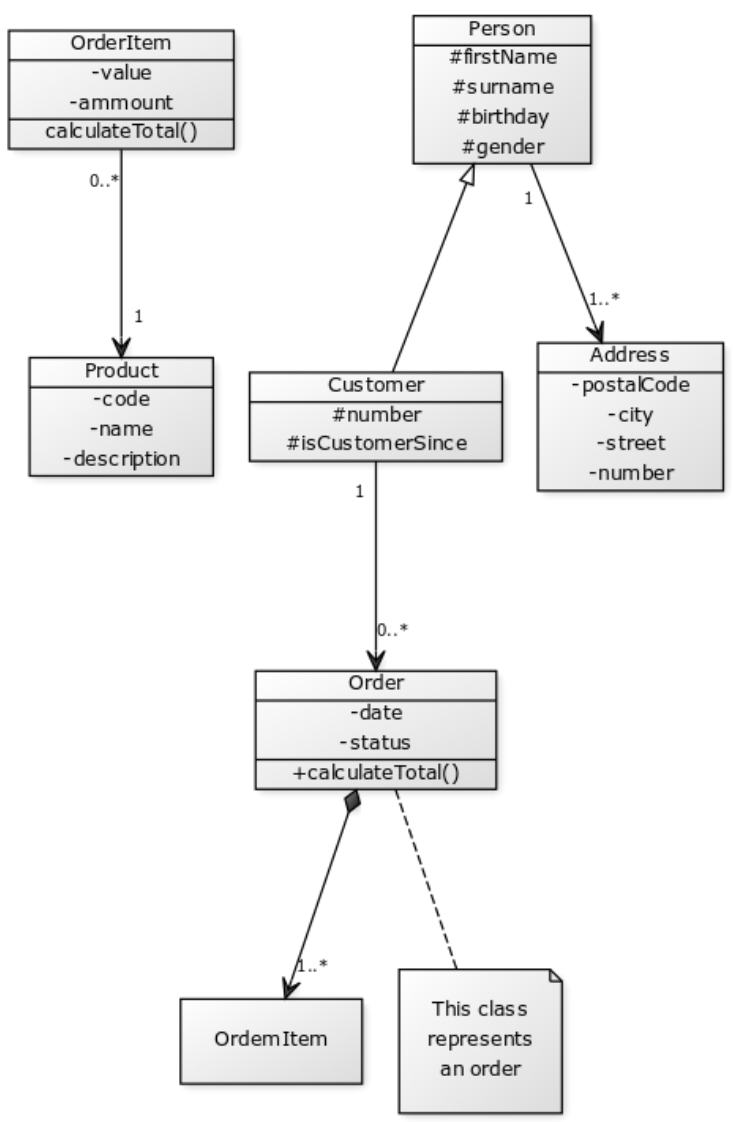

Figure 3: Class diagram generated by yUML.

Therefore, the functional requirements to perform such activities are listed by referring to user stories [74] from the sighted participants, blind participants and general participants, relating each requirement to the activities (i), (ii), (iii), (iv) and (v), as summarized in tables 3, 4 , and 5 , respectively. In these tables, the columns are the five type of activities and the rows are the functional requirements.

\begin{tabular}{|c|c|c|c|c|c|c|}
\hline \multirow{6}{*}{ 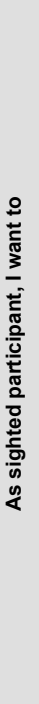 } & User Story & $\mathbf{i}$ & ii & iii & iv & v \\
\hline & $\begin{array}{l}\text { 1: create and edit diagrams } \\
\text { using the graphical UML } \\
\text { notation }\end{array}$ & $\checkmark$ & $\checkmark$ & $\checkmark$ & & \\
\hline & $\begin{array}{l}\text { 2: follow changes in diagram } \\
\text { editing activities through the } \\
\text { graphical UML notation in } \\
\text { order to understand and } \\
\text { collaborate }\end{array}$ & & $\checkmark$ & & & \\
\hline & $\begin{array}{l}\text { 3: have access to diagrams } \\
\text { created by sighted participants } \\
\text { through the graphical UML } \\
\text { notation }\end{array}$ & & & & $\checkmark$ & $\checkmark$ \\
\hline & $\begin{array}{l}\text { 4: have access to diagrams } \\
\text { created by blind participants } \\
\text { through the graphical UML } \\
\text { notation }\end{array}$ & & & & $\checkmark$ & $\checkmark$ \\
\hline & $\begin{array}{l}5 \text { : follow the highlights made } \\
\text { by other participant during } \\
\text { activities and navigate }\end{array}$ & $\checkmark$ & $\checkmark$ & $\checkmark$ & & \\
\hline
\end{tabular}

throughout the highlighted elements using the graphical UML notation, to be able to follow the explanation and collaborate

Table 3: Functional requirements: sighted participants

\begin{tabular}{|c|c|c|c|c|c|c|}
\hline \multirow{6}{*}{ 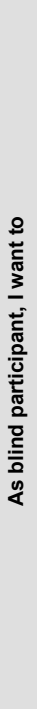 } & User Story & i & ii & iii & iv & $v$ \\
\hline & $\begin{array}{l}\text { 6: create and edit accessible } \\
\text { diagrams }\end{array}$ & $\checkmark$ & $\checkmark$ & $\checkmark$ & & \\
\hline & $\begin{array}{l}\text { 7: be able to follow changes in } \\
\text { diagram editing activities in } \\
\text { order to understand and } \\
\text { collaborate }\end{array}$ & & $\checkmark$ & & & \\
\hline & $\begin{array}{l}\text { 8: be able to access the } \\
\text { diagrams created by the } \\
\text { sighted participants }\end{array}$ & & & & $\checkmark$ & $\checkmark$ \\
\hline & $\begin{array}{l}\text { 9: be able to access the } \\
\text { diagrams created by the blind } \\
\text { participants }\end{array}$ & & & & $\checkmark$ & $\checkmark$ \\
\hline & $\begin{array}{l}\text { 10: follow the highlights made } \\
\text { by other participant during } \\
\text { activities and navigate } \\
\text { throughout the highlighted } \\
\text { elements in order to be able to } \\
\text { follow the explanation and } \\
\text { collaborate }\end{array}$ & $\checkmark$ & $\checkmark$ & $\checkmark$ & & \\
\hline
\end{tabular}

Table 4: Functional requirements: blind participants

\begin{tabular}{|c|c|c|c|c|c|c|}
\hline \multirow[b]{2}{*}{ 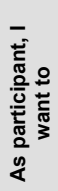 } & User Story & $\mathbf{i}$ & ii & iii & iv & $\mathbf{v}$ \\
\hline & $\begin{array}{l}\text { 11: highlight elements of the } \\
\text { diagrams I am presenting, } \\
\text { creating or editing, so other } \\
\text { participants can follow the } \\
\text { explanations and collaborate }\end{array}$ & $\checkmark$ & $\checkmark$ & $\checkmark$ & & \\
\hline
\end{tabular}

Table 5: General functional requirements

Some of these requirements have different purposes for instructors and learners. Table 6 describes their purposes according to the reasons for being relevant to the instructor or the learner.

\begin{tabular}{l|l|l}
\hline \multicolumn{1}{c|}{ Requirements } & \multicolumn{1}{|c}{ Instructor } & \multicolumn{1}{c}{ Learner } \\
\hline 1,6 & $\begin{array}{l}\text { Prepare presentations and } \\
\text { delivery content to learners }\end{array}$ & $\begin{array}{l}\text { Elaborate assign- } \\
\text { ments and exams }\end{array}$ \\
\hline $3,4,8,9$ & $\begin{array}{l}\text { Evaluate assignments and } \\
\text { exams }\end{array}$ & $\begin{array}{l}\text { Access course } \\
\text { materials and make } \\
\text { peer reviews }\end{array}$
\end{tabular}

Table 6: Purposes for using the requirements.

The requirements related to the manner learners and instructors comment on diagrams in evaluation or review activities was not considered as this is generally accomplished by text.

Regardless of referring to only blind people, these requirements are valid for including other people with any degree of visual impairment. 


\section{Requirements Fulfillment: what is currently available}

None of the solutions/tools available in the review fulfill all of the requirements needed considering the existence of spatial distance. Table 7, presents the relation between the reviewed studies and the established requirements. "P" indicates a partially fulfilled requirement and a blank indicates a requirement that is not fulfilled. In order to check the requirements fulfillment for each solution/tool that implements interaction with CASE tools, it was considered twice: with and without combination of the CASE tool.

\begin{tabular}{|c|c|c|c|c|c|c|c|c|c|c|c|}
\hline \multirow[b]{2}{*}{ Study } & \multicolumn{11}{|c|}{ Requirements } \\
\hline & 1 & 2 & 3 & 4 & 5 & 6 & 7 & 8 & 9 & 10 & 11 \\
\hline $\begin{array}{l}\text { Owen et } \\
\text { al. [9] - } \\
\text { Audible } \\
\text { Browser }\end{array}$ & & & & & & & & $\checkmark$ & $\checkmark$ & & \\
\hline $\begin{array}{l}\text { Audible } \\
\text { Brows- } \\
\text { er+CASE } \\
\text { tools }\end{array}$ & $\checkmark$ & $\checkmark$ & $\checkmark$ & $\checkmark$ & $\checkmark$ & & & $\checkmark$ & $\checkmark$ & & $P$ \\
\hline Müller [17] & $\checkmark$ & $\checkmark$ & $\checkmark$ & $\checkmark$ & $\checkmark$ & & & $\checkmark$ & & $\checkmark$ & $\checkmark$ \\
\hline $\begin{array}{l}\text { Brookshire } \\
\text { [20] }\end{array}$ & $P$ & $P$ & $P$ & $P$ & $\checkmark$ & $\checkmark$ & $\checkmark$ & $\checkmark$ & $\checkmark$ & $\checkmark$ & $\checkmark$ \\
\hline $\begin{array}{l}\text { King et al. } \\
{[67]}\end{array}$ & & & $\checkmark$ & $\checkmark$ & & & & $\checkmark$ & $\checkmark$ & & \\
\hline $\begin{array}{l}\text { Accessible } \\
\text { UML } \\
\text { +CASE } \\
\text { tools }\end{array}$ & $\checkmark$ & $\checkmark$ & $\checkmark$ & $\checkmark$ & $\checkmark$ & & & $\checkmark$ & $\checkmark$ & & $P$ \\
\hline $\begin{array}{l}\text { Pansanato } \\
\text { et al. [68] }\end{array}$ & & & & & & & & & & & \\
\hline And & & & $\checkmark$ & $\checkmark$ & & $\checkmark$ & & & $\checkmark$ & & \\
\hline $\begin{array}{l}\text { Santos et } \\
\text { al. [69] - } \\
\text { D4ALL }\end{array}$ & & & & & & & & & & & \\
\hline $\begin{array}{l}\text { D4ALL+C } \\
\text { ASE tools }\end{array}$ & $\checkmark$ & $\checkmark$ & $\checkmark$ & $\checkmark$ & $\checkmark$ & $\checkmark$ & & $\checkmark$ & $\checkmark$ & & $\mathrm{P}$ \\
\hline $\begin{array}{l}\text { Silva et al. } \\
\text { [70] }\end{array}$ & & & & & & $\checkmark$ & & & $\checkmark$ & & \\
\hline $\begin{array}{l}\text { Grillo et al. } \\
{[71]-} \\
\text { AWMo }\end{array}$ & $\checkmark$ & $\checkmark$ & $\checkmark$ & $\checkmark$ & & $\checkmark$ & $\checkmark$ & $\checkmark$ & $\checkmark$ & & \\
\hline $\begin{array}{l}\text { Metatla et } \\
\text { al. [72] - } \\
\text { CCml }\end{array}$ & $\checkmark$ & $\checkmark$ & $\checkmark$ & $\checkmark$ & & $\checkmark$ & $\checkmark$ & $\checkmark$ & $\checkmark$ & & \\
\hline $\begin{array}{l}\text { Loitsch \& } \\
\text { Weber } \\
{[73]-} \\
\text { Hy- } \\
\text { perReader } \\
\text { +Visio }\end{array}$ & $\checkmark$ & $\checkmark$ & $\checkmark$ & $\checkmark$ & $\checkmark$ & & $\checkmark$ & $\checkmark$ & $\checkmark$ & & $P$ \\
\hline
\end{tabular}

P to blind participants, since it allows accessing and designing diagrams by using worksheets, thus preventing the interaction of those participants who do not know such representation form.

Regarding the web-based textual UML tools, they should be appropriate for integration with e-LE. Nevertheless, most of them only allow the generation of diagrams from text but not the reverse; therefore, only fulfilling requirements 4, 6 and 9. Additionally, they do not implement all UML diagrams - non implemented diagrams are marked with a grey column in Table 1. Exceptions are AWMo and $\mathrm{CCml}$, both meeting most of the requirements previously mentioned.

In this context, it is relevant to conduct studies that seek identifying methods for meeting the functional requirements 5,10 , and 11 ; thence, allow more interactivity in e-learning activities of UML, with little impact from transactional distance. 


\section{On The Development of a Prototype}

This section presents some details on the prototype development of a web-based tool (Inclusive UML) that fulfills the proposed requirements. The information presented in this section can be useful for researchers interested in implementing similar tools. A free version of the tool will be made available by the publication date.

In software development projects, the first implementation relating decision concerns to whether to create it as an extension of an existing code or as an independent solution. For this case, the decision was between creating an UML CASE tool add-on or an independent solution. The development of thirty-party add-ons can be difficult as it involves new code integration, which is limited by the existing code and structure. Also, requirements 5, 10 and 11 may be impossible to implement in some tools as they require functionality of being the listeners of selection events (e.g. when a user clicks on a diagram element). Considering this and the fact that portability is a desired non-functional requirement, the prototype is implemented as an independent web-based solution.

Our decisions concerning technological support were: (i) adopting an existing framework to leverage the development effort and to profit from the tested components; (ii) using design patterns for providing synchronization during collaborative activities; and (iii) reusing a DSL for providing textual description of UML diagrams. In addition, some rules were defined to avoid inconsistency during collaboration (share-lock and sound information regarding the edition of diagrams for collaborative approaches).

Therefore, considering that for requirements 1, 2, 3 and 4, the prototype must present graphical UML and allow editing, existing frameworks were adopted in the development of the prototype. Additionally, the use of existing frameworks does not impose any limitation to the prototype. The frameworks considered were jsUML2 ${ }^{1}$, Jumly ${ }^{2}$, and JointJS ${ }^{3}$. They are all Javascript libraries that allow the implementation of visual diagramming, including editing. jsUML2 was adopted because it is a free software (GNU GPL v3) and implements 9 types of UML diagrams. The others were discarded because Jumly implements only sequence diagrams, and JointJS requires a commercial license for the diagramming tools.

The accessible version of a diagram, related to requirements 6,8 , and 9 , was implemented through textual DSL, based on the yUML DSL, and keyboard shortcuts

\footnotetext{
${ }^{1}$ https://code.google.com/p/jsuml2/

${ }^{2}$ http://jumly.tmtk.net/

${ }^{3}$ http://jointjs.com/demos/umlcd
}

for interaction. This way, sighted and blind people may have access to different views for the same diagram. On one hand, a sighted participant can access and edit a diagram through a graphical interface using the UML standard notation. On the other hand, a blind participant can access and edit diagrams through a text-based interface.

To keep these different views synchronized, what is necessary for the collaboration previewed in the requirements $2,5,7,10$, and 11 , the Observer design pattern [75] was implemented. This design pattern involves two main roles: observable and observer. An observable is any element, generally an object in an object-oriented programming language, which changes must result in a notification to its observers. An observer, by its time, is an element that must be notified when an observable has changed. For synchronization purposes, the diagram metadata is the observable. It contains the information from the model represented by the diagram and from graphical properties, such as the position of an element and colors, among others. The different views of the diagram are registered as observers and, when it changes, they are updated.

Despite Observer design pattern promoting the required synchronization for collaboration, there were other important aspects related to how concurrent changes are managed. There are additional difficulties originated from the manner changes are perceived by sighted and blind people in a collaborative set. For sighted people, there are a lot of literature available in cross-modal collaborative work [76, 77]. However, for sighted and blind people, there are some research gaps [78] concerning the viability of blind and sighted people working together on the same element at the same time, as well as presenting information changes performed by other participants.

Some rules were adopted for the prototype, such as: each diagram element has a shared-lock; therefore, when an user is changing the element, other users cannot change it. When an user starts changing an element, a yellow box surrounding the element is presented in the graphical representation. For the text-based interface, a short bell song is produced when another user starts changing an element. In addition, there are shortcuts which can be used to access the information of what each participant is doing at the moment. This information is presented by phrases, such as "User $\mathrm{X}$ is editing the use case A" or "User $\mathrm{Y}$ has just removed the association between the Use Case A and Actor B".

Finally, it is important to note that some special requirements had to be considered; for instance, it is recommended to follow the Web accessibility guidelines to make the webpages accessible to blind people. This includes the use of specific HTML tags and attributes, such as $<\mathrm{html}$ lang $>$, and <img alt $>$, among others. 


\section{Conclusions and Future Work}

This paper presented the main challenges for the inclusion of blind participants in interactive e-learning activities involving UML, aiming at reducing the impact of transactional distance, by establishing the necessary requirements of web-based tools. Existing approaches were reviewed along with solutions and tools for inclusion of blind people, according with the fulfillment of the proposed requirements.

The results indicated the lack of tools able to meet all of the requirements meaning that, currently, it is not fully possible to include the participation of blind people in UML e-learning activities without suffering from the impact of transactional distance. Further research and technology development effort are necessary to change this scenario.

In order to contribute with technology capable of fulfilling the requirements here proposed by filling the existing gaps and by other researchers working in this field, an web-based prototype called Inclusive UML was developed and will be made available to public as free software.

As for future work, usability experiments will be conducted with blind and sighted students in a simulated academic setting in order to validate and evolve the developed prototype.

Other future researches must address the study of appropriated interface/interaction styles involving collaboration between blind and sighted participants (requirements 2, 5, 7, 10, and 11). Examples of the questions remaining open include: how to inform blind participants about concurrent changes in a diagram? Is providing audio alerts enough? Is Haptic feedback necessary? When these change notifications should be presented? May shared audio contribute to a scenario with several participants?

\section{Acknowledgments}

This work received funding from the TOSHIBA Scholarship Program through the Escola Politécnica University of Sao Paulo, grant 2014/Dr-02 (TOSHIBAEPUSP).

\section{References}

[1] World Health Organization, Visual Impairment and Blindness: fact sheet n. 282, http://www.who.int/mediacentre/factsheets/fs282 /en/, Mar. 2015.
BGE. Demographic Census 2010. The Brazilian Institute of Geography and Statistics, Rio de Janeiro, 2010.

[3] C. Power, A. Freire, H. Petrie et al. Guidelines Are Only Half of the Story: accessibility problems encountered by blind users on the web. In Proceedings of the SIGCHI Conference on $\mathrm{Hu}$ man Factors in Computing Systems, Texas, 433$442,2012$.

[4] E. Gerber. The benefits of and barriers to computer use for individuals who are visually impaired. Journal of Visual Impairment \& Blindness, 97: 536-550, 2003.

[5] P. P. S. Chen. The Entity-Relationship Model toward a unified view of data. ACM Transactions on Database Systems, 1(1): 9-36, 1976.

[6] Y. L. Chen. Data Flow Diagram. In Modeling and Analysis of Enterprise and Information Systems. Springer. 85-97, 2009.

[7] J. Rumbaugh, I. Jacobson, G. Booch, The Unified Modeling Language Reference Manual, Pearson Higher Education, 2004.

[8] B. Dobing, J. Parsons. How UML is Used. Communications of the ACM, 49: 109-113, 2006.

[9] C. B. Owen, S. Coburn, M. J. Castor. Teaching Modern Object-Oriented Programming to the Blind: an instructor and learner experience. In ASEE Annual Conference, 2014.

[10] ACM/AIS. Curriculum guidelines for undergraduate degree programs in Information Systems, 2010.

[11] ACM/IEEE. Computer science curriculum 2008: an interim revision of CS 2001. Report from the interim review task force, 2008.

[12] ACM/IEEE. Curriculum guidelines for undergraduate degree programs in information technology, 2008.

[13] IEEE/ACM. Curriculum guidelines for undergraduate degree programs in computer engineering, 2004.

[14] IEEE/ACM. Curriculum guidelines for undergraduate degree programs in software engineering, 2004.

[15] IEEE/ACM. Curriculum guidelines for graduate degree programs in software engineering, 2009.

[16] OMG, Unified Modeling Language, http://www.omg.org/spec/UML/, Mar. 2015. 
[17] K. Müller. How to Make Unified Modeling Language Diagrams Accessible for Blind Learners. Lecture Notes in Computer Science, 7382: 186-190, 2012.

[18] C. Loitch, W. Gerhard. Viable Haptic UML for Blind People. Lecture Notes in Computer Science, 7383: 509-516, 2012.

[19] A. M. Gilkes, M. W. Cowens, L. A. Taylor U.S. Patent No. 5580251. Washington, DC: U.S. Patent and Trademark Office, 1996.

[20] R. G. Brookshire. Teaching UML Database Modeling to Visually Impaired Learners. Issues in Information Systems, 7(1): 98-101, 2006.

[21] D. McMullen, D. Fitzpatrick. Autonomous access to graphics for visually impaired learners, Irish Educational Technology User's Conference, http://ilta.ie/files/DeclanMcMullenEdTech2009.pdf, 2009.

[22] R. Tori. Educação sem distância. Senac. 2010

[23] K. M. Alonso. A expansão do ensino superior no Brasil e a EaD: dinâmicas e lugares. Educação \& Sociedade, 31(113): 1319-1335, 2010.

[24] M. Arrigo. E-learning accessibility for blind students, Proceedings of The Third International Conference on Multimedia and Information \& Communication Technologies in Education, 2005.

[25] Ministério da Educação, Instituição de Ensino Superior e Cursos Cadastrados, http://emec.mec.gov.br/, Mar. 2015.

[26] J. Arata, H. Kondo, N. Ikedo et al. Haptic device using a newly developed redundant parallel mechanism, IEEE Transactions on Robotics, 27(2): 201-214, 2011.

[27] Moore, M. G. Theory of transactional distance. Theoretical principles of distance education, 22, 1993.

[28] D. McCallum, S. Ungar, S. Jehoel. An evaluation of tactile directional symbols, British Journal of Visual Impairment, 24(2): 83-92, 2006.

[29] R. W. Massof. Auditory assistive devices for the blind, International Conference on Auditory Display, Boston, pages 271-275, 2003.

[30] K. Christian. Design of haptic and tactile interfaces for blind users. Department of Computer Science, University of Maryland, 2000.

[31] S. Ina. Computer graphics for the blind, $A C M$ SIGCAPH Computers and the Physically Handi- capped, 55: 16-23, 1996.

[32] R. Ivanov. Indoor navigation system for visually impaired, Proceedings of the 11th International Conference on Computer Systems and Technologies and Workshop for PhD Learners in Computing on International Conference on Computer Systems and Technologies, ACM, pages pp. 143$149,2010$.

[33] E. Penterich. Virtual learning environments (Ambientes virtuais de aprendizagem). São Paulo: Editora da Universidade Metodista de São Paulo, 2005.

[34] Moodle, https://moodle.org, Mar. 2015.

[35] Blackboard, https://www.blackboard.com, Mar. 2015.

[36] Tidia-AE, http://tidia-ae.usp.br/download/, Mar. 2015.

[37] Teleduc, www.teleduc.org.br/, Mar. 2015.

[38] L. Luque, R. R. Silva. Acessibilidade em Java, Java Magazine, 96, Rio de Janeiro, 2011.

[39] S. D. Piovesan, R. Wagner, R. D. Medina et al. Sistema Imersivo para Pessoas com Deficiência, Anais do Simpósio Brasileiro de Informática na Educação, 24(1), 2013.

[40] E. D. Tabs, T. Waits, L. Lewis. Distance education at degree-granting postsecondary institutions: 2000-2001. Washington: US Department of Education, 2003.

[41] L. Luque, E. Veriscimo, G. Pereira et al. Can We Work Together? On the Inclusion of Blind People in UML Model-Based Tasks. In P. M. Langdon, J. Lazar, A. Heylighen et al. (eds.) Inclusive Design. Springer. 223-233, 2014.

[42] AWMo, Accessible Web Modeler, http:/garapa.intermidia.icmc.usp.br:3000/awmo/ , Mar. 2015.

[43] Blockdiag, Interactive shell for block diag, http://interactive.blockdiag.com/, Mar. 2015.

[44] Codeuml, http://codeuml.com/, Mar. 2015.

[45] Ckwnc, UML sequence diagram editor, http://www.ckwnc.com/, Mar. 2015.

[46] Diagrammr, http://www.diagrammr.com/, Mar. 2015 .

[47] Finite State Machine Diagram Editor and Source Code Generator, http://www.stateforge.com/StateMachineDiagra $\mathrm{m} /$ StateMachineDiagram.html, Mar. 2015. 
[48] Js-sequence-diagrams, http://bramp.github.io/jssequence-diagrams/, Mar. 2015.

[49] MetaUML Live, http://metauml.denksoft.com/, Mar. 2015.

[50] Nomnoml, http://www.nomnoml.com/, Mar. 2015.

[51] PlantTextUML Editor, http://www.planttext.com/, Mar. 2015.

[52] PlantUML, http://plantuml.sourceforge.net/, Mar. 2015.

[53] SeedUML, https://seeduml.com/voh10, Mar. 2015.

[54] Sequence Flow, http://sullerandras.github.io/SVG-SequenceDiagram/, Mar. 2015.

[55] UMLEtino, http://www.umletino.com/, Mar. 2015.

[56] Umple, http://cruise.site.uottawa.ca/umple/, Mar. 2015.

[57] WebSequenceDiagram, https://www.websequencediagrams.com/order.ht ml, Mar. 2015.

[58] yUML, http://yuml.me/, Mar. 2015.

[59] EventStudio, http://www.eventhelix.com/EventStudio/, Mar. 2015.

[60] LightUML, http://lightuml.sourceforge.net/, Mar. 2015.

[61] Modsl, https://code.google.com/p/modsl/, Mar. 2015.

[62] Quick Sequence Diagram Editor, http://sdedit.sourceforge.net/index.html, Mar. 2015.

[63] TextUML Toolkit, http://abstratt.github.io/textuml/readme.html, Mar. 2015.

[64] UMLGraph, http://www.umlgraph.org/, Mar. 2015.

[65] UMLet, http://www.umlet.com/overview.html, Mar. 2015.

[66] USE, http://useocl.sourceforge.net/, Mar. 2015.

[67] A. King, P. Blenkhorn, D. Crombie et al. Presenting UML software engineering diagrams to blind people, Computers Helping People with Special Needs, pages 522-529, Springer Berlin
Heidelberg, 2004.

[68] L. T. E. Pansanato, A. L. M. Bandeira, L. G. D. Santos et al. Projeto D4ALL: acesso e manipulação de diagramas por pessoas com deficiência visual, Proceedings of the 11th Brazilian Symposium on Human Factors in Computing Systems, pages 33-36, 2012.

[69] L. G. Santos, A. L. Bandeira, Pansanato, L. T. et al. Recursos de acessibilidade para auxiliar a navegação de estudantes cegos em um editor de diagramas, Anais do Simpósio Brasileiro de Informática na Educação, 23 (1), 2012.

[70] C. E. Silva, L. T. Pansanato, J. A. Fabri. Ensinando diagramas UML para estudantes cegos, Anais do XVIII CIESC-XXXVI CLEI, 2010.

[71] F. D. N. Grillo, R. P. de Mattos Fortes, D. Lucrédio. Towards collaboration between sighted and visually impaired developers in the context of Model-Driven Engineering, http://www.dsmforum.org/events/gmld12/papers /Grillo.pdf, 2012.

[72] O. Metatla, N. Bryan-Kinns, T. Stockman et al.. Cross-modal collaborative interaction between visually impaired and sighted users in the workplace,

https://smartech.gatech.edu/jspui/bitstream/1853/ 44430/18/Metatla_ICAD2012.pdf, 2012.

[73] C. Loitsch, G. Weber. Viable haptic UML for blind people, Computers Helping People with Special Needs, pages 509-516, Springer Berlin Heidelberg, 2012.

[74] N. C. Haugen. An empirical study of using planning poker for user story estimation, Agile Conference, IEEE, 2006.

[75] E. Gamma, R. Helm, R. Johnson, et al. Design patterns: elements of reusable object-oriented software. Pearson Education, 1994.

[76] J. C. Tang. Findings from observational studies of collaborative work, International Journal of Man-machine studies, 34(2): 143-160, 1991.

[77] J. W. Strijbos. Assessment of (computersupported) collaborative learning, IEEE Transactions on Learning Technologies, 4(1): 59-73, 2011.

[78] O. Metatla, N. Bryan-Kinns, T. Stockman et al. Supporting cross-modal collaboration in the workplace, Proceedings of the 26th Annual BCS Interaction Specialist Group Conference on People and Computers, pages 109-118). British 
Computer Society, 2012. 